\title{
Electrical Discharge Surface Alloying of Superalloy Haynes 230 with Aluminum and Molybdenum
}

\author{
Ching-Yuan Bai ${ }^{1, * 1}$, Chun-Hao Koo ${ }^{1, * 2}$ and Che-Chung Wang ${ }^{2}$ \\ ${ }^{1}$ Department of Materials Science and Engineering, National Taiwan University, Taipei 10617, Taiwan, R.O. China \\ ${ }^{2}$ Department of Industrial Design, Shih Chien University, Taipei 10462, Taiwan, R.O. China
}

\begin{abstract}
Surface alloying of superalloy Haynes 230 was performed using either Al-Mo mixture powders suspended in kerosene or Al-Mo composite electrode during the electrical discharge alloying (EDA). For suspending Al-Mo powders in kerosene, the $\mathrm{Cr}_{23} \mathrm{C}_{6}, \mathrm{WC}_{1-x}$, and graphite phases exist in the alloyed layer of the EDA specimen with negative electrode polarity, while the specimen with positive electrode polarity exhibits no alloying phase except the raw material phase. For employing the Al-Mo electrode with negative polarity, the specimen represents many discontinuous piled-layers, with $\mathrm{Al}_{3} \mathrm{Mo}_{8}$ and $\mathrm{AlMo}_{3}$ phases accumulating on the substrate surface. The specimen produced using Al-Mo electrode with positive polarity shows an alloyed layer constituted mainly with NiAl phase. This specimen also shows the smallest surface roughness and highest hardness among the four EDA specimens. The kinetics of isothermal oxidation at $1000^{\circ} \mathrm{C}$ in static air demonstrate that the specimen using Al-Mo electrode with positive polarity possesses the best oxidation resistance among the tested specimens.
\end{abstract}

(Received May 31, 2004; Accepted July 28, 2004)

Keywords: Electrical discharge alloying (EDA), composite electrode, alloyed layer, piled-layer, isothermal oxidation.

\section{Introduction}

Electrical discharge alloying (EDA) is an effective means of using a green-compact composite electrode ${ }^{1-4)}$ or adding metal powders in the dielectric fluid, ${ }^{5-7)}$ and thus improving the surface chemical and mechanical properties of structure materials. The energy from the electrical arc can melt the surfaces of both composite electrode and workpiece, and can decompose the dielectric. ${ }^{8,9)}$ The molten electrode droplets, metal powder suspended in dielectric fluid, and/or decomposed dielectric elements transfer to a molten discharge crater of a substrate surface to form an alloyed or composite layer. The EDA modified layer, which is obtained relatively rapidly, possesses sufficient engineering thickness and hardness. ${ }^{10)}$ The thickness and hardness of this modified layer can be controlled by EDA parameters. ${ }^{2,10)}$ The EDA modified layer with a compositional gradient shows excellent adhesion to the substrate. ${ }^{2)}$ Furthermore, selecting the electrode material and working fluid, which may contain alloying powders, can readily control the composition of the modified layer. ${ }^{2,6)}$ Therefore, manipulating the EDA parameters and selecting applicable alloying materials can achieve a surface chemistry with improved resistance to wear, corrosion, and high temperature oxidation and corrosion failures.

$\mathrm{Al}$ and Mo are important constituents of Ni-based superalloys, which have found been widely applied as high temperature structural materials under complex loading conditions in aggressive environments. Combined with certain other alloying elements, these two elements are known to impart high temperature strength and creep resistance to superalloys through forming intermatallic precipitates like $\gamma^{\prime}\left(\mathrm{L}_{2}\right)$ and $\gamma^{\prime \prime}\left(\mathrm{DO}_{22}\right)$ phases. ${ }^{11)}$ The system of Ni-Mo alloys exhibits several attractive features, like $\{11 / 20\}$ spinodal ordering and the continuous evolution of equilibrium and metastable ordered phases, such as $\mathrm{Ni}_{3} \mathrm{Mo}$

\footnotetext{
${ }^{* 1}$ Graduate Student, National Taiwan University

${ }^{* 2}$ Corresponding author, E-mail: chkoo@ccms.ntu.edu.tw
}

$\left(\mathrm{DO}_{22}\right)$ and $\mathrm{Ni}_{4} \mathrm{Mo}\left(\mathrm{D} 1_{\mathrm{a}}\right)$, from the spinodally ordered alloy. ${ }^{12,13)}$ Additionally, binary $\mathrm{Ni}-\mathrm{Al}$ alloys such as $\mathrm{Ni}_{3} \mathrm{Al}$ and $\mathrm{NiAl}$ phases have attracted considerable research attention in terms of their structure and protective application owing to their superior mechanical performance and good corrosion resistance at high temperature. ${ }^{14,15)}$ Furthermore, Al-Mo alloys or alloying common metals with $\mathrm{Al}$ and Mo recently have been confirmed to possess excellent resistance to individual or simultaneous oxidation and sulfidation because of the formation of protective corrosion products such as $\mathrm{Al}_{2} \mathrm{O}_{3}, \mathrm{MoS}_{2}$, and $\mathrm{Al}_{0.55} \mathrm{Mo}_{2} \mathrm{~S}_{4} \cdot{ }^{16-18)}$

Electrical discharge surface alloying of Ni-based superalloy Haynes 230 with aluminum and molybdenum is thus expected to improve its resistance of wear and high temperature oxidation and corrosion. The EDA process included the use of Al-Mo composite electrode and the suspension of AlMo mixture powders in dielectric fluid. The present work attempts to understand the influence of different EDA conditions on surface alloying, and also investigates the surface properties of various EDA specimens.

\section{Experimental Details}

\subsection{EDA process}

The raw material examined in this study is the nickelbased superalloy Haynes 230 manufactured by Haynes international Inc. Table 1 lists the chemical composition of the alloy. A conventional electrical discharge machine, like that shown in the experimental set-up of Fig. 1, was utilized to modify the surface of the superalloy. The mixture of 85 at $\% \mathrm{Al}$ powders $(10-15 \mu \mathrm{m}$, degree of purity $=99.95 \%)$ and 15 at\% Mo powders $(10-15 \mu \mathrm{m}$, degree of purity = $99.95 \%$ ), mixed in a cylindrical shape blender for 12 hours, was used as the surface alloying material. The Al-Mo mixture powders were fabricated to a green-compact composite electrode, bonded to an electrolytic copper rod with copper conductive mounting compound, using powder metallurgy under $80 \mathrm{MPa}$ at $250^{\circ} \mathrm{C}$ for $50 \mathrm{~min}$. This work used the 
Table 1 The chemical composition of the experimental superalloy Haynes 230.

\begin{tabular}{|c|c|c|c|c|c|c|c|c|c|c|c|c|}
\hline Elements & $\mathrm{Ni}$ & $\mathrm{Cr}$ & W & Co & $\mathrm{Fe}$ & Mo & $\mathrm{Mn}$ & $\mathrm{Si}$ & $\mathrm{Al}$ & $\mathrm{C}$ & $\mathrm{La}$ & B \\
\hline & & & & $\operatorname{Max}$ & $\operatorname{Max}$ & & & & & & & Max \\
\hline $\mathrm{Wt} \%$ & 57 & 22 & 14 & 5 & 3 & 2 & 0.5 & 0.4 & 0.3 & 0.1 & 0.02 & 0.015 \\
\hline
\end{tabular}

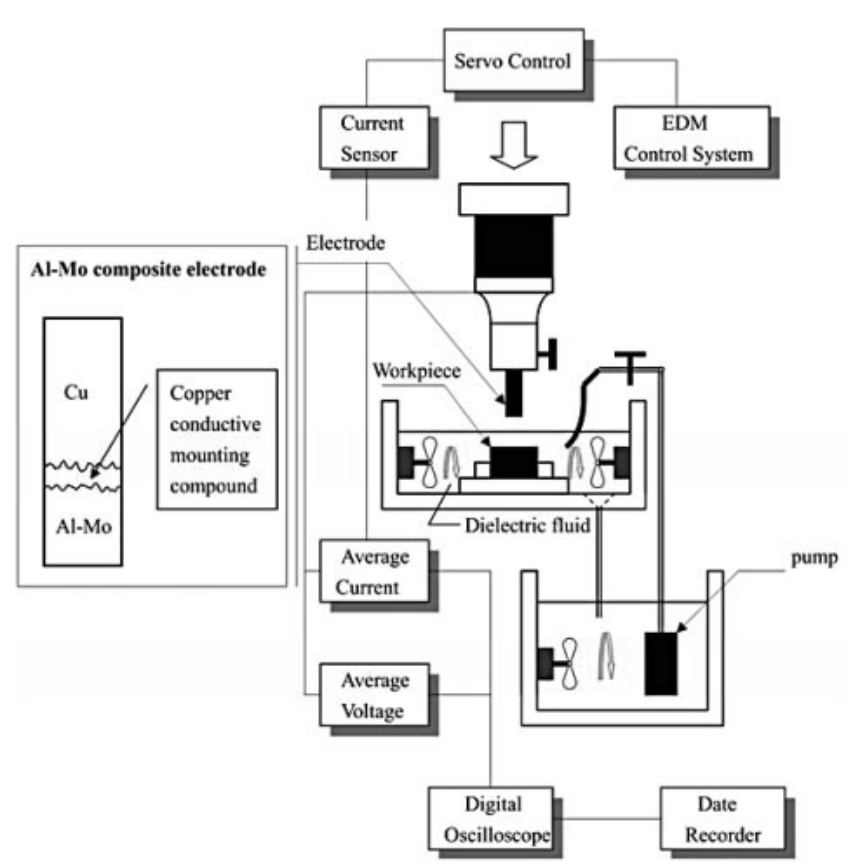

Fig. 1 Schematic diagram of EDA experimental apparatus.

method of either employing composite electrode or powders suspended in dielectric fluid for EDA process. For using AlMo composite electrode, commercial kerosene was circulated as the dielectric fluid in the tank during surface alloying. For the method of powders suspended in dielectric fluid, the Al-Mo mixture powders were added to kerosene, which was cycled by the additive dielectric cyclic system to distribute the added powder evenly, while an electrolytic copper rod served as the electrode material. Both positive and negative electrode polarity were used to compare the alloying results with different polarities. Table 2 lists the actual experimental conditions of the EDA process.

Four surface alloying specimens, prepared via the EDA process using (1) the Al-Mo electrode with positive polarity in pure kerosene dielectric, (2) Al-Mo electrode with negative polarity in pure kerosene dielectric, (3) $\mathrm{Cu}$ electrode with positive polarity in dielectric of kerosene with Al-Mo mixture powders, and (4) $\mathrm{Cu}$ electrode with negative polarity in dielectric of kerosene with Al-Mo mixture powders, were named P-AlMo-Kero, N-AlMo-Kero, P-Cu-Kero(AlMo), and $\mathrm{N}-\mathrm{Cu}-\mathrm{Kero}(\mathrm{AlMo})$, respectively.

\subsection{Analysis and testing of alloyed specimens}

Following the EDA process, the alloyed specimens were cut to $\phi 12 \mathrm{~mm}$ via wire electrical discharge machining then ultrasonically cleaned with acetone and distilled water. The alloyed specimens were analyzed by X-ray diffraction (XRD, Siemens D-5000 diffractometer with emission power condition of $30 \mathrm{kV}$ and $40 \mathrm{~mA}$ ) using monochromatic $\mathrm{Cu}-\mathrm{K} \alpha$
Table 2 The EDA experimental conditions.

\begin{tabular}{ll}
\hline Working parameters & \multicolumn{1}{c}{ Description } \\
\hline Work piece & $\begin{array}{c}\text { Superalloy Haynes } 230 \\
(15 \mathrm{~mm} \times 15 \mathrm{~mm} \times 2 \mathrm{~mm})\end{array}$ \\
Electrode & $\begin{array}{c}\text { (1) Al-Mo composite electrode }(\phi 12 \mathrm{~mm}), \\
(85 \mathrm{at} \% \mathrm{Al}-15 \mathrm{at} \% \mathrm{Mo})\end{array}$ \\
& $\begin{array}{l}\text { (2) Cu solid electrode }(\phi 12 \mathrm{~mm}) \\
\text { (1) Kerosene }\end{array}$ \\
& (2) Kerosene with Al-Mo mixture powders \\
& $(10 \mathrm{~g} /$ liter $)$ \\
Electrode polarity & Positive $(+) /$ negative $(-)$ \\
Discharge current, $I_{\mathrm{p}}$ & $10 \mathrm{~A}$ \\
Pulse duration, $\tau_{\mathrm{p}}$ & $600 \mu \mathrm{s}$ \\
Duty factor & 0.33 \\
Rotation speed & $3.77 \mathrm{~m} \cdot \mathrm{s}^{-1}$ \\
of electrode & $360 \mathrm{~s}$ \\
Working time &
\end{tabular}

Al-Mo electrode forming pressure/ temperature/time: $80 \mathrm{MPa} / 250^{\circ} \mathrm{C}$ / $50 \mathrm{~min}$.

radiation with a characteristic wavelength of $0.1542 \mathrm{~nm}$ to identify the various phases of the EDA modified layer and underlayer alloys. Scanning electron microscopy (SEM) then was employed to examine the surface morphology and crosssectional microstructure. Additionally, X-ray energy dispersive spectrometry (EDS) and electron probe microanalysis (EPMA) were used to analyze the chemical composition of the alloyed specimens. The surface roughness presented by center-line average (Ra) was measured with a precision profilometry. Five random measurements of $\mathrm{Ra}$ were averaged to determine the typical surface roughness. Moreover, the hardness profiles of the EDA specimens were measured along the depth of the cross-section, using a Knoop hardness tester with a load of $25 \mathrm{~g}$ and a loading time of $15 \mathrm{~s}$. Finally, the high temperature oxidation test subjected the EDA specimens, which are alloyed on two-side surfaces, and unalloyed superalloy to isothermal oxidation at $1000^{\circ} \mathrm{C}$ in static air for 41 days, but both were weighted at 24 hour intervals to calculate the oxidation kinetics.

\section{Results and Discussion}

\subsection{Phase analysis}

XRD analysis was performed on unalloyed superalloy Haynes 230 and four EDA specimens, and the results are illustrated in Figs. 2(a)-(e). The superalloy shows a disordered face centered cubic solid solution, $\gamma$ phase, containing some solute elements, such as $\mathrm{Cr}, \mathrm{Mo}, \mathrm{Co}, \mathrm{Fe}$, and $\mathrm{W}$, based on the combination of XRD with EPMA analyses.

The $\mathrm{NiAl}, \mathrm{Al}_{8} \mathrm{Mo}_{3}, \mathrm{Cr}_{23} \mathrm{C}_{6}$, and $\mathrm{Al}_{4} \mathrm{C}_{3}$ phases are detected in the alloyed layer of P-AlMo-Kero, except for the peaks of Haynes 230 for the case selecting Al-Mo composite electrode 


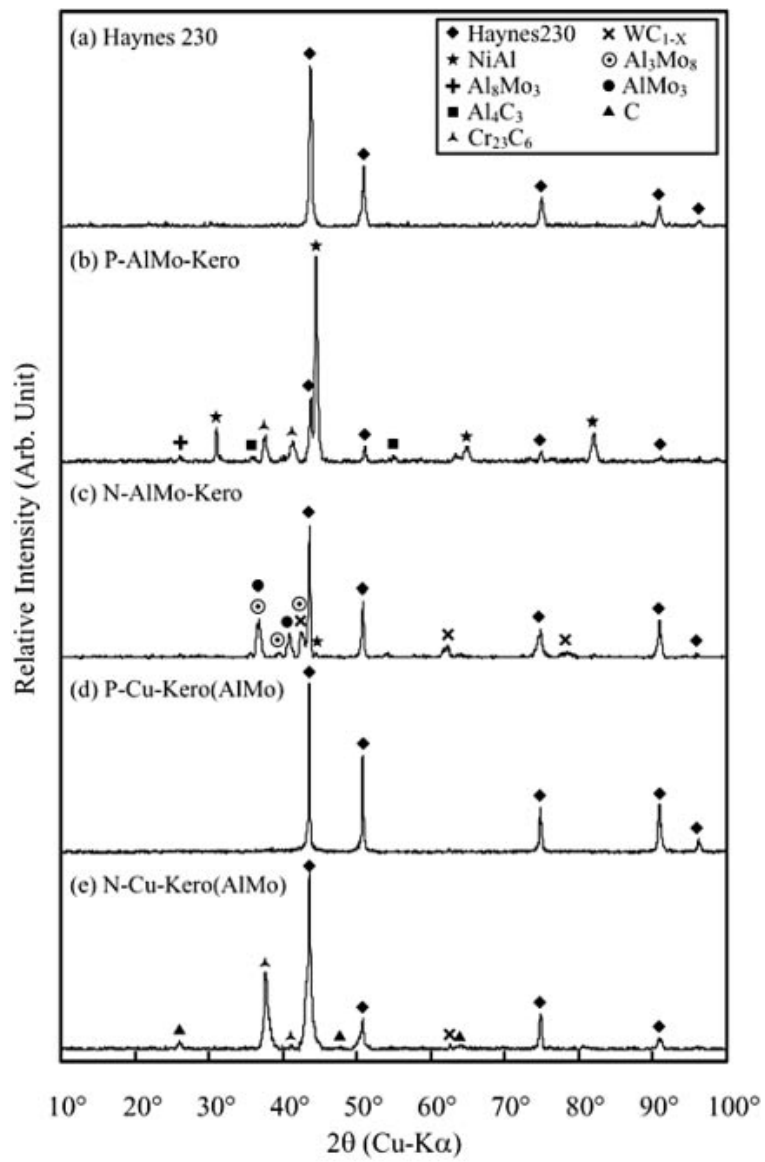

Fig. 2 XRD diffraction patterns of (a) superalloy Haynes 230, (b) P-AlMoKero, (c) N-AlMo-Kero, (d) P-Cu-Kero(AlMo), and (e) N-Cu-Kero(AlMo) specimens.

with positive polarity. Meanwhile, the intensity of $\mathrm{NiAl}$ peaks in the XRD spectra of P-AlMo-Kero is considerably stronger than that of other phases demonstrating that the $\mathrm{NiAl}$ phase is the main constituent of the alloyed layer of the PAlMo-Kero specimen. During electrical discharge, the AlMo composite electrode is partially molten due to elevated temperature from the electrical arc, and at this moment, the kerosene fluid is decomposed to provide carbon for the EDA process. These alloying elements of $\mathrm{Al}, \mathrm{Mo}$, and $\mathrm{C}$ react with themselves and transfer to the molten surface of the superalloy, and then react with the elements of the substrate through successive pulsed discharge arcs between an electrode and workpiece. Consequently, the carbides of $\mathrm{Al}_{4} \mathrm{C}_{3}$ and $\mathrm{Cr}_{23} \mathrm{C}_{6}$ as well as intermetallics of $\mathrm{NiAl}$ and $\mathrm{Al}_{8} \mathrm{Mo}_{3}$ in situ form in the alloyed layer of P-AlMo-Kero. For the NAlMo-Kero specimen, XRD analysis shows the presence of $\mathrm{Al}_{3} \mathrm{Mo}_{8}, \mathrm{AlMo}_{3}, \mathrm{WC}_{1-x}$, and $\mathrm{NiAl}$ in the alloyed layer, but $\mathrm{NiAl}$ peaks have very low intensity in the XRD pattern. This phenomenon indicates that the alloying elements of $\mathrm{Al}$ and Mo obtained from the disintegrated electrode cannot effectively dissolve into the fused surface of the substrate to form alloying phases, but the alloying elements almost react by themselves and are attached to the substrate surface.

The X-ray diffraction result of $\mathrm{P}-\mathrm{Cu}-\mathrm{Kero}(\mathrm{AlMo})$ specimen shows a pattern of the raw material indicating that no alloying phase forms on the specimen surface besides the $\gamma$ phase. The Al-Mo mixture powders suspended in the kerosene cannot effectively transfer to the molten surface of the substrate to form an alloyed layer in this experiment. For another EDA specimen involving the addition of Al-Mo mixture powders in kerosene, the $\mathrm{XRD}$ pattern of $\mathrm{N}-\mathrm{Cu}$ Kero(AlMo) represents that the $\mathrm{Cr}_{23} \mathrm{C}_{6}, \mathrm{WC}_{1-x}$, and carbon (graphite phase) exist in the alloyed layer, indicating that large quantities of carbon decomposed from kerosene diffuse or mix into the molten region of the superalloy, and then some carbons react with $\mathrm{Cr}$ or $\mathrm{W}$; other carbons disperse in the alloyed layer. However, the alloying elements of $\mathrm{Al}$ and Mo may dissolve slightly into the substrate to form a solid solution, or may be unable to effectively transfer to the molten surface.

In Ni-based superalloys system, the carbide phase $\mathrm{MC}$, in which $\mathrm{M}$ can be $\mathrm{Cr}$, Mo, or $\mathrm{W}$, forms upon solidification of the alloy but disappears during aging at lower temperature. On the other hand, $\mathrm{M}_{23} \mathrm{C}_{6}$ is stable at temperatures below $875^{\circ} \mathrm{C}$, but not at higher temperatures. ${ }^{11)}$ Moreover, the standard free energies of formation of $\mathrm{Cr}_{23} \mathrm{C}_{6}, \mathrm{Al}_{4} \mathrm{C}_{3}$, and $\mathrm{WC}$ at $1726 \mathrm{~K}$, the melting point of nickel, are -443.5 , -101 , and $-34 \mathrm{~kJ} / \mathrm{mol}$, respectively, calculated based on the thermodynamic data from the JANAF tables. ${ }^{19)}$ Comparing the standard free energies of formation of $\mathrm{Al}_{4} \mathrm{C}_{3}$ with other carbides, $\mathrm{Al}_{4} \mathrm{C}_{3}$ is expected to react with $\mathrm{Cr}$ in an equilibrium reaction at the melting point of nickel. The present work finds that the $\mathrm{WC}_{1-x}$, a non-stoichiometric phase, exists in $\mathrm{N}$ AlMo-Kero, while the $\mathrm{Cr}_{23} \mathrm{C}_{6}$ and $\mathrm{WC}_{1-x}$ phases are found in the $\mathrm{N}-\mathrm{Cu}-\mathrm{Kero}(\mathrm{AlMo})$ specimen. Additionally, the $\mathrm{Cr}_{23} \mathrm{C}_{6}$ and $\mathrm{Al}_{4} \mathrm{C}_{3}$ are detected in P-AlMo-Kero. These phenomenons demonstrate that the carbides presented in EDA specimens are in a metastable state.

During the electrical discharge process, the thermal energy converted from electrical energy melts the surface of Al-Mo electrode and the superalloy, and decomposes the kerosene dielectric. The carbon decomposed from the kerosene and the molten electrode materials would be induced into the molten surface of the superalloy to form a molten mixture. The molten mixture would quickly resolidify in the kerosene to form numerous compounds (including stable and metastable phases) due to the effect of rapid melting and resolidification. The main constituent phases existing in the alloyed layer and underlying alloy of the EDA specimens have been analyzed by the X-ray diffraction pattern, as shown in Fig. 2. However, some reflections diffracted from the minor constituents are very weak and difficult to identify via X-ray diffraction. Because of the limited ability of the analytical apparatus, $\mathrm{XRD}$, these weak peaks, as shown in the paper, are just for reference.

\subsection{Microstructure and element distribution of alloyed layers}

Figure 3 shows the cross-sectional micrographs with EDS line scan of P-AlMo-Kero. The alloyed layer of P-AlMoKero has a thickness of approximately $40 \mu \mathrm{m}$ and bonds strongly to the substrate. The alloying elements, Al, Mo, and $\mathrm{C}$, are distributed in the alloyed layer with a compositional gradient that decreases gradually from the surface to the substrate, while the signal intensities of $\mathrm{Ni}, \mathrm{Cr}$, and $\mathrm{W}$, the main elements of substrate, increase with distance from the 

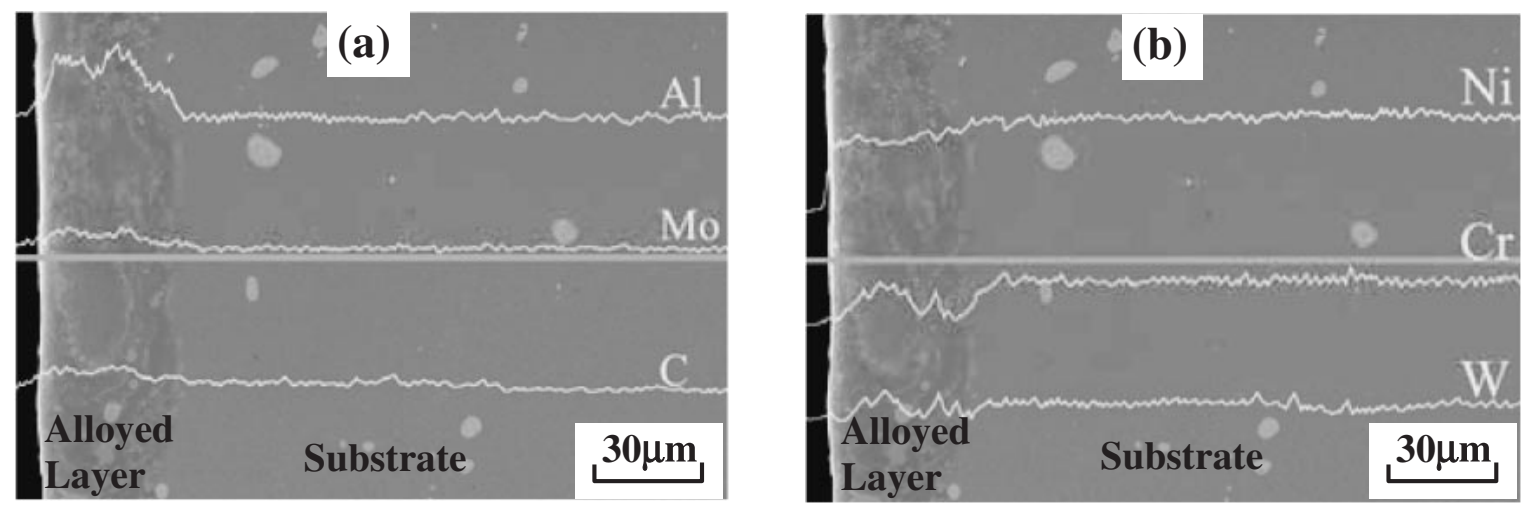

Fig. 3 Cross-section SEM micrographs with EDS line scan for (a) Al, Mo, C, and (b) Ni, Cr, W of the P-AlMo-Kero.

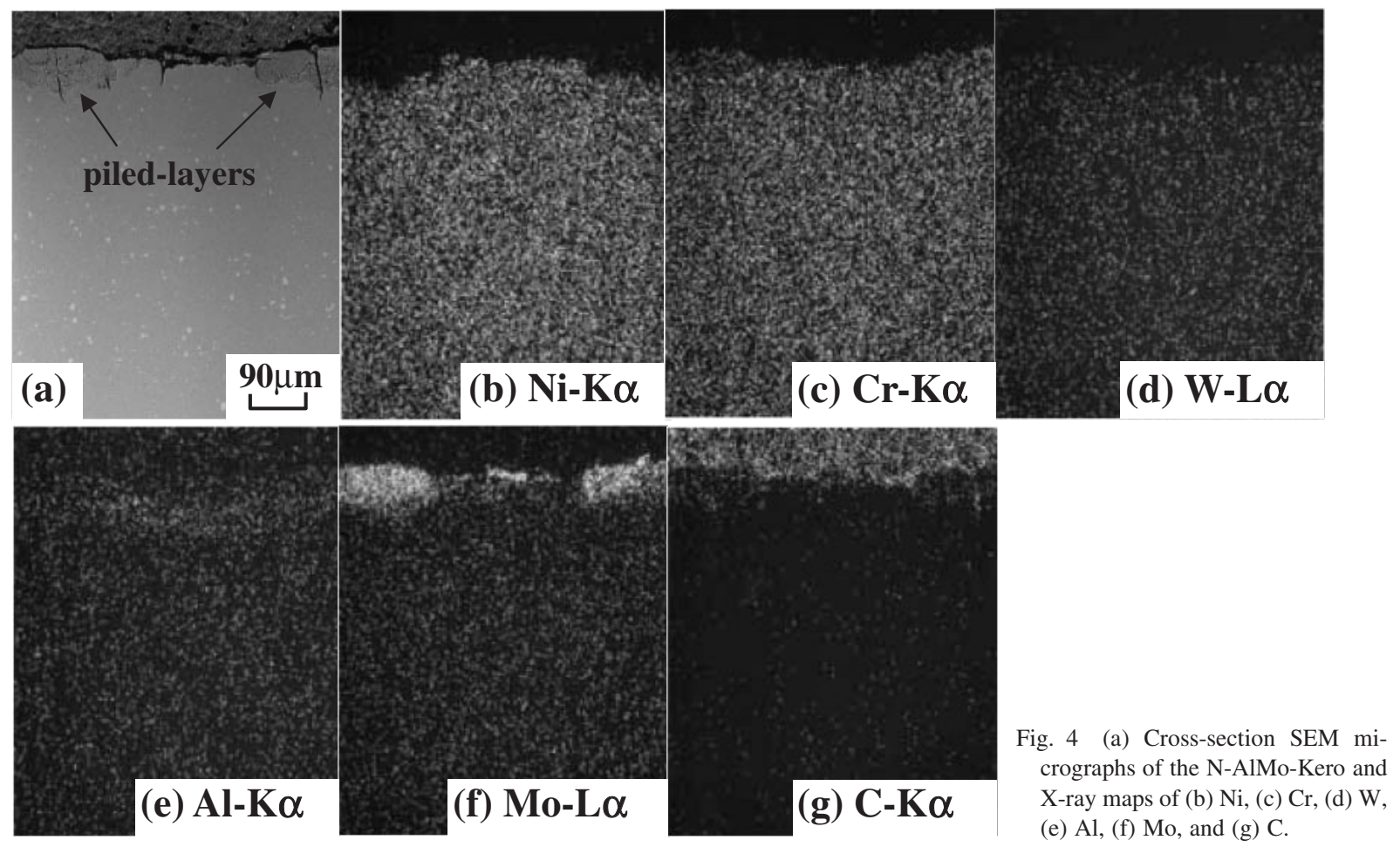

surface. The fact of a compositional gradient recognized in the elemental distribution indicates that the alloyed layer on the surface of this specimen is highly resistant to peel off, which is a typical feature of modified layer produced by the coating or alloying processes. Figure 4 illustrates typical SEM cross-sectional images and corresponding X-ray maps of N-AlMo-Kero. Contrary to the formation of homogeneous alloyed layer on the surface of P-AlMo-Kero, discontinuous piled layers containing large amounts of Mo and little amounts of $\mathrm{Al}$ are formed and attached on the surface of $\mathrm{N}$ AlMo-Kero, and serious cracks are produced through the pilled layers. From the X-ray maps of the N-AlMo-Kero specimen, small quantities of $\mathrm{Al}$ are also observed in the shallow depth of the substrate, indicating that the $\mathrm{Al}$ and $\mathrm{Mo}$ tend to separate from the mixture of electrode droplets when the mixture accumulates on the surface of the superalloy in this EDA condition.

The different alloying results between P-AlMo-Kero and $\mathrm{N}$-AlMo-Kero specimens result from the influence of electrode polarity. The anode has a larger discharge spot than the cathode, and the current or energy density of anode is smaller than that of cathode in the same EDM condition. ${ }^{20-22)}$ When the composite electrode has positive polarity, the discharge spot on the electrode is larger and results in a wider melting zone than that on the workpiece. Although the current density on the electrode with positive polarity is lower than that on the substrate, the discharge energy is sufficient to decompose many particles from the weakly bonding electrode and drop them on the molten substrate surface. Furthermore, a deep molten zone is yielded on the substrate surface owing to its larger current density, such that alloying materials transferred from the electrode dissolve successfully into the molten substrate surface to produce an alloyed layer. On the other hand, when the electrode is cathode, the current density on the electrode is higher than that on the substrate. High electrode energy density results in high electrode consumption, and consequently large amounts of electrode particles are produced and drop to the substrate. 
However, lower discharge energy yields a shallow molten substrate surface. The shallow molten zone may quickly resolidify in the work fluid. Moreover, the melting point of Mo $\left(2617^{\circ} \mathrm{C}\right)$ is far higher than that of superalloy Haynes 230 (1301-1371 $\left.{ }^{\circ} \mathrm{C}\right)$. Consequently, little Al dissolves in shallow substrate depth, while large amounts of electrode materials, especially for Mo element, cannot effectively mix into the substrate. Therefore, Mo-rich intermetallics, such as $\mathrm{Mo}_{3} \mathrm{Al}$ and $\mathrm{Mo}_{8} \mathrm{Al}_{3}$ identified according to XRD analysis shown in Fig. 2, are formed on the substrate surface in the style of discontinuous piled-layers, harming surface properties. The EDA outcome of selecting negative electrode polarity therefore is worse than that of using positive electrode polarity as the result of employing a weakly bonding electrode. This inference from the experimental results is related to the composition and forming conditions, for example the forming pressure and temperature, of the composite electrode, and further study is required to identify suitable EDA parameters for specific electrode and workpiece.

The cross-sectional micrograph with EDS line scan of P$\mathrm{Cu}$-Kero(AlMo), illustrated in Fig. 5, shows that the signal intensities of $\mathrm{Al}, \mathrm{Mo}$, and $\mathrm{C}$ are almost constant from surface to substrate, and numerous cracks exist in the recast layer (RCL). Negative polarity machining (positive electrode polarity) with higher impulsive force on the workpiece produces a higher material removal rate (MRR) than does positive polarity machining. Additionally, the conductive powders of $\mathrm{Al}$ and Mo, suspended in the working fluid, assist ignition by increasing the discharge probability and reducing the breakdown strength of the insulating dielectric fluid, thus increasing the MRR. ${ }^{23-25)}$ Accordingly, the transfer of

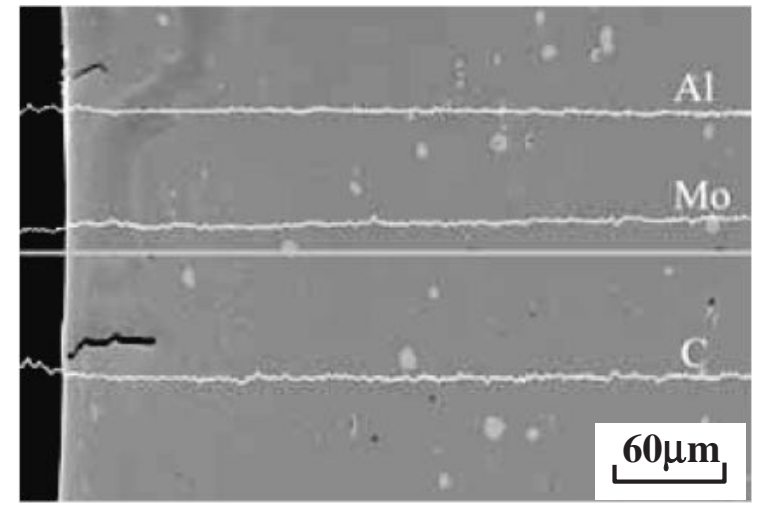

Fig. 5 Cross-section SEM micrograph with EDS line scan for Al, Mo, and $\mathrm{C}$ of the P-Cu-Kero(AlMo).

alloying elements into the machined surface is invalid because of the high MRR of this experimental condition.

Figures 6(a)-(g) show the cross-sectional micrograph of $\mathrm{N}-\mathrm{Cu}-\mathrm{Kero}(\mathrm{AlMo})$ and the corresponding X-ray maps of $\mathrm{Ni}$, $\mathrm{Cr}, \mathrm{W}, \mathrm{Al}, \mathrm{Mo}$, and $\mathrm{C}$. The alloyed layer with depth of approximately $35 \mu \mathrm{m}$ contains many dark precipitates differing in size and inconsistently dispersed in the layer. EDS analysis reveals that small size precipitates contain fair $\mathrm{Cr}$ and $\mathrm{C}$, however, large size precipitates mainly comprise carbon, besides small quantities of $\mathrm{Cr}$ and $\mathrm{W}$ on the edges of precipitates. X-ray maps of $\mathrm{Al}$ also reveal that the $\mathrm{Al}$ content near the surface is slightly higher than that of the substrate. On the other hand, the signal of Mo content is constant throughout the specimen. Because the density of Mo $\left(10.22 \mathrm{~g} / \mathrm{cm}^{3}\right.$ at $\left.20^{\circ} \mathrm{C}\right)$ is almost four times that of $\mathrm{Al}$
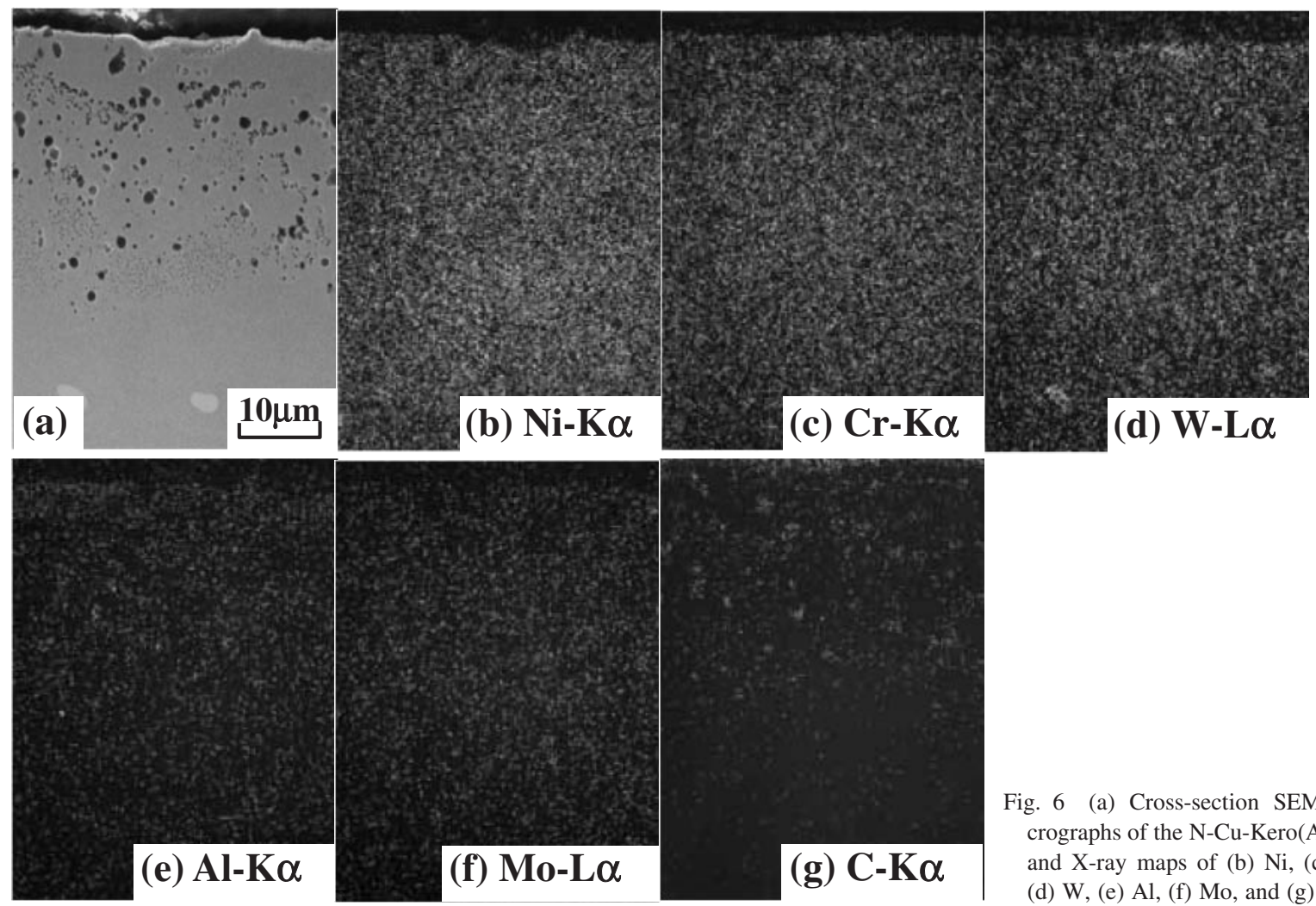

Fig. 6 (a) Cross-section SEM micrographs of the $\mathrm{N}-\mathrm{Cu}-\mathrm{Kero}(\mathrm{AlMo})$ and X-ray maps of (b) $\mathrm{Ni}$, (c) $\mathrm{Cr}$, (d) W, (e) Al, (f) Mo, and (g) C. 

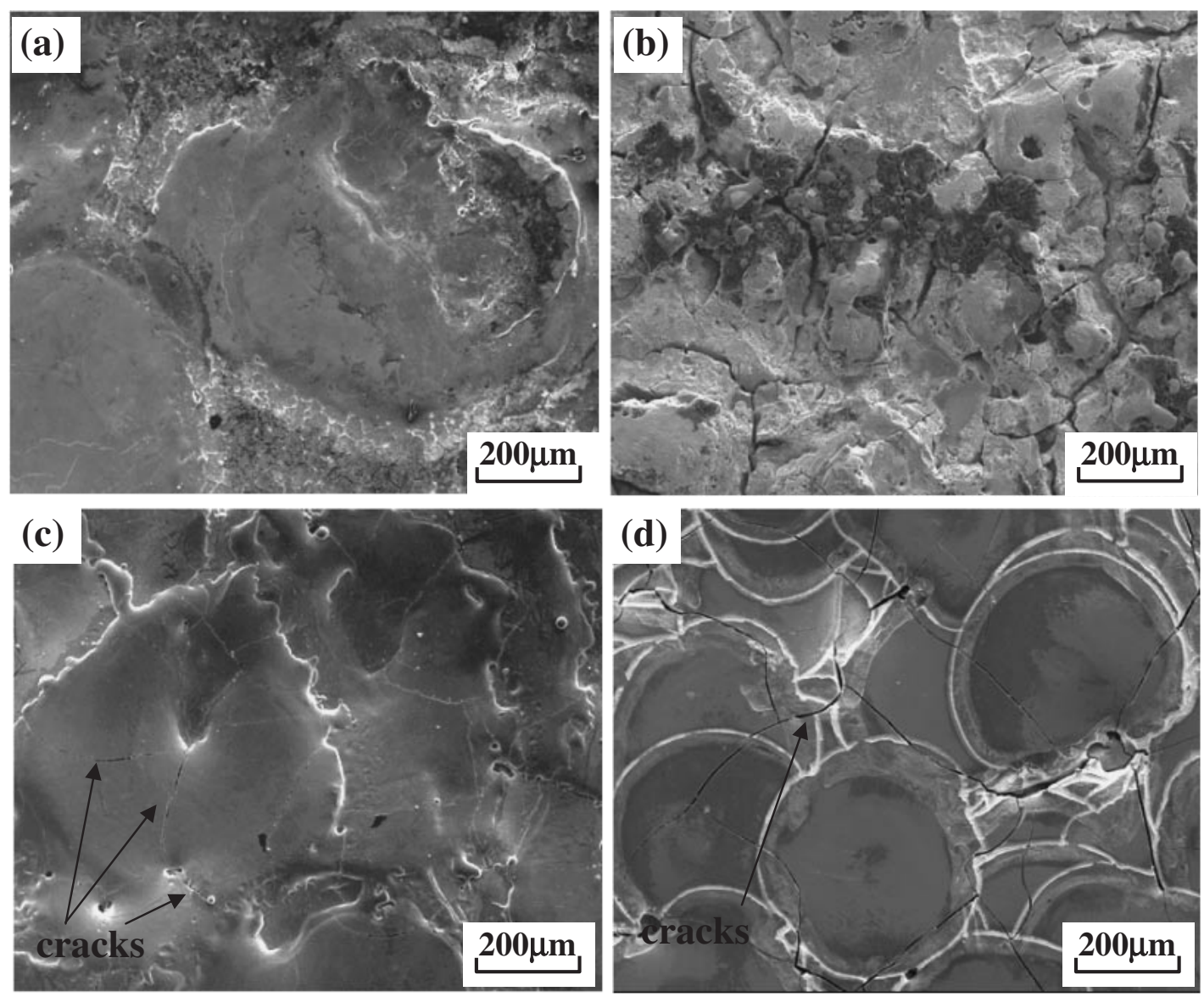

Fig. 7 Surface morphologies of (a) P-AlMo-Kero, (b) N-AlMo-Kero, (C) P-Cu-Kero(AlMo), and (d) N-Cu-Kero(AlMo) specimens.

$\left(2.7 \mathrm{~g} / \mathrm{cm}^{3} \text { at } 20^{\circ} \mathrm{C}\right)^{26)}$ and the content of Mo is significantly less than that of $\mathrm{Al}$ in the mixture powders, the suspensions of Mo powders in kerosene are disproportionate and inadequate. Therefore, Mo cannot effectively transfer to the machined surface. Additionally, the carbon anions decomposed from hydrocarbon dielectric accumulate on the surface of superalloy (anode) and then penetrate or mix into the substrate melting zone. Some carbon reacts with $\mathrm{Cr}$ to form $\mathrm{Cr}_{23} \mathrm{C}_{6}$ phase, while other carbon coarsens and disperses in the alloyed layer of the specimen because of a lack of time to enable complete carbon reaction with the substrate elements during a very short solidification period.

The experimental results of carbide formation and $\mathrm{Al}$ dissolution in the alloyed layer agree with a previous investigation $^{10)}$ reporting surface modification of SKD 61 by adding $\mathrm{Al}$ and $\mathrm{Cr}$ powders in the kerosene and the use of $\mathrm{Cu}$ electrode with positive polarity machining (negative electrode polarity) during EDM. However, the modification of surface chemical properties by little $\mathrm{Al}$ dissolving in the alloyed layer and the increase of surface mechanical properties by inconsistently dispersing carbides in the alloyed layer are limited. Moreover, the coarsening carbon in the alloyed layer would damage the chemical and mechanical properties of the superalloy during high temperature operations.

Based on the analyses of the composition and microstructure of the alloyed or recast layers, the alloying effect from adding metal powders in dielectric fluid is worse than that from using composite electrode during the EDA process.

\subsection{Surface roughness measurements}

Figures 7(a)-(d) illustrate the surface morphologies of alloying specimens under various EDA conditions, and Fig. 8 shows the surface roughness of these specimens. The PAlMo-Kero specimen with the finest surface morphologies demonstrates the smallest surface roughness $(R a=2.62 \mu \mathrm{m})$, followed in sequence by the $\mathrm{N}-\mathrm{Cu}-\mathrm{Kero}(\mathrm{AlMo}), \mathrm{P}-\mathrm{Cu}-$ Kero(AlMo), and N-AlMo-Kero specimens. The phenomenon of the P-AlMo-Kero specimen having the finest surface morphology is attributed to the Al-Mo composite electrode having low thermal conductivity, enabling the alloying materials to disintegrate from the electrode and reside onto the work-piece surface, then mix with molten surface of superalloy to smooth the surface and reduce crack production. However, N-AlMo-Kero has the coarsest surface morphology among four EDA specimens, and has a roughness of $R a=5.68 \mu \mathrm{m}$. In the EDA process involving the use of Al-Mo composite electrode with negative polarity, high electrode consumption and shallow molten surface of the superalloy produce numerous rough mounds, which are mixtures of Mo and Al, attaching on the surface of N-AlMoKero specimen. The rough mounds exhibit discontinuous piled-layers and many serious cracks in cross-sectional observation of this specimen.

For the surface alloying specimens involving the addition of Al-Mo mixture powders in kerosene, many surface cracks are yielded on the specimens of P-Cu-Kero(AlMo) and N$\mathrm{Cu}-\mathrm{Kero}(\mathrm{AlMo})$ due to rapid resolidification of the molten 


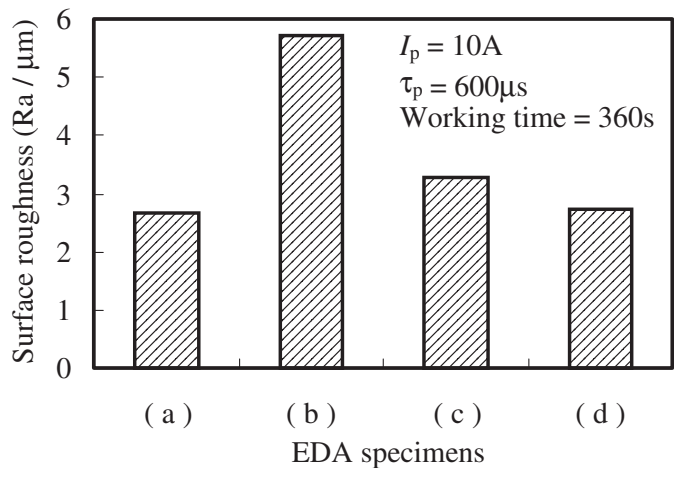

Fig. 8 Surface roughness of (a) P-AlMo-Kero, (b) N-AlMo-Kero, (C) P$\mathrm{Cu}-\mathrm{Kero}(\mathrm{AlMo})$, and (d) N-Cu-Kero(AlMo) specimens.

surface in work fluid. The alloying elements of $\mathrm{Al}$ and Mo transfer to the surface of the workpiece ineffectively thus preventing significant crack reduction. However, during electrical discharge, the discharge current is divided to the conductive powders of $\mathrm{Al}$ and Mo to reduce the discharge energy of the single discharge column. The Al-Mo mixture powders also reduce the breakdown strength of the insulating dielectric fluid to increase the gap distance and reduce the impulsive force. Consequently, the surface morphology of $\mathrm{P}$ $\mathrm{Cu}-\mathrm{Kero}(\mathrm{AlMo})$ and $\mathrm{N}-\mathrm{Cu}-\mathrm{Kero}(\mathrm{AlMo})$ is smooth, and the roughness is almost equivalent to that of the P-AlMo-Kero specimen, indicating that electrical discharge machining with conductive powders added to the kerosene dielectric is a feasible method of modifying surface roughness.

\subsection{Hardness measurements}

Figure 9 shows the cross-sectional hardness profiles of the EDA specimens. For all EDA specimens, the maximum hardness occurs close to the surface, and the profiles decrease from the surface to substrate. The maximum hardness of PAlMo-Kero with effective alloying results is approximately $1100 \mathrm{HK}$, and the hardness profiles of this specimen agrees with the compositional gradient analysis of alloying elements in the alloyed layer shown in Fig. 3. The increase in surface hardness of P-AlMo-Kero specimen after EDA process

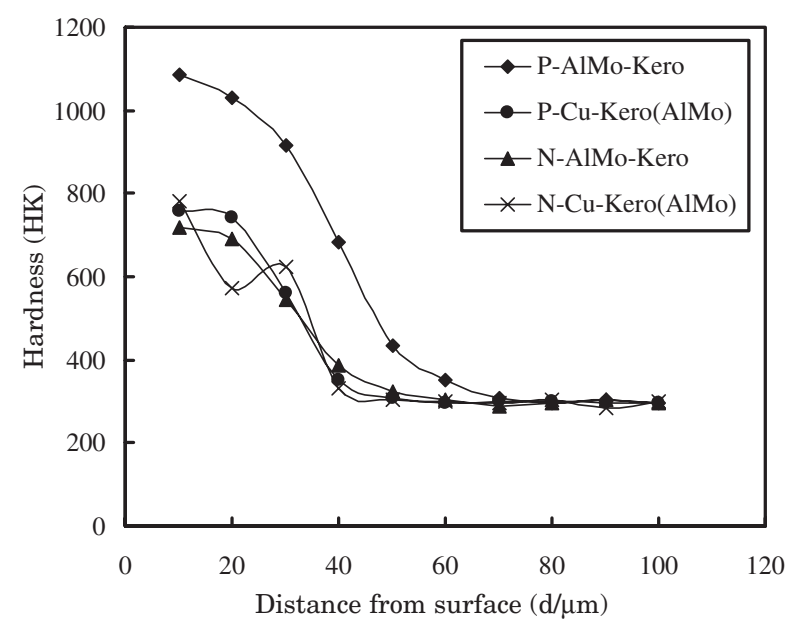

Fig. 9 Hardness profiles along the depth of cross-section of the EDA specimens. (load: $25 \mathrm{~g}$, loading time: $15 \mathrm{~s}$ ) results from the quenching effect and the formation of intermetallics such as $\mathrm{NiAl}$ and $\mathrm{Al}_{8} \mathrm{Mo}_{3}$ in the alloyed layer. The intermetallics have an ordered structure, and thus the alloyed layer of P-AlMo-Kero has higher hardness than the base metal.

To avoid variant results, the hardness of N-AlMo-Kero is measured on a cross-section without piled layers due to the discordant character of discontinuous piled-layers. The maximum hardness of $\mathrm{N}$-AlMo-Kero, $\mathrm{P}-\mathrm{Cu}-\mathrm{Kero}(\mathrm{AlMo})$, and $\mathrm{N}-\mathrm{Cu}-\mathrm{Kero}(\mathrm{AlMo})$ specimens with invalid alloying results are all in a lower than that of N-AlMo-Kero but narrow range of 720-780, and the higher hardness profiles of these specimens are all in heat affected layers at depths of around $30-50 \mu \mathrm{m}$. This phenomenon indicates that the hardness of these specimens is enhanced not by alloying but primarily by the quenching effect. Additionally, the hardness profile of $\mathrm{N}-\mathrm{Cu}-\mathrm{Kero}(\mathrm{AlMo})$ is variant because of inhomogeneous dispersion of graphite and carbides in the alloyed layer.

\subsection{High temperature oxidation test}

Figure 10 shows the isothermal oxidation kinetics of unalloyed and variously alloyed superalloy Haynes 230 specimens at $1000^{\circ} \mathrm{C}$. The isothermal oxidation behavior of the superalloy follows the parabolic rate law up to 600 hours, and shows a gradual weight loss after 600 hours. This behavior indicates that oxide scales forming on the surface of the superalloy can act as a diffusion barrier during the early stage of oxidation; however, the superalloy lacks long-term oxidation resistance.

The kinetic curve of P-AlMo-Kero specimen demonstrates a very low weight gain, and follows the parabolic rate law even following 41 days of exposure, indicating that the alloyed layer formed on the surface of this specimen produces a protective oxide layer acting as a diffusion barrier and possess long-term oxidation resistance. On the other hand, the oxidation resistance of other alloyed specimens; NAlMo-Kero, N-Cu-Kero(AlMo), and P-Cu-Kero(AlMo) is even worse than that of unalloyed superalloy. The N-AlMoKero exhibits a weight loss during the initial stage of oxidation because of the formation of volatile molybdenum oxide. ${ }^{27)}$ The P-Cu-Kero(AlMo) shows considerable weight losses after $24 \mathrm{~h}$ of oxidation caused by oxide scale

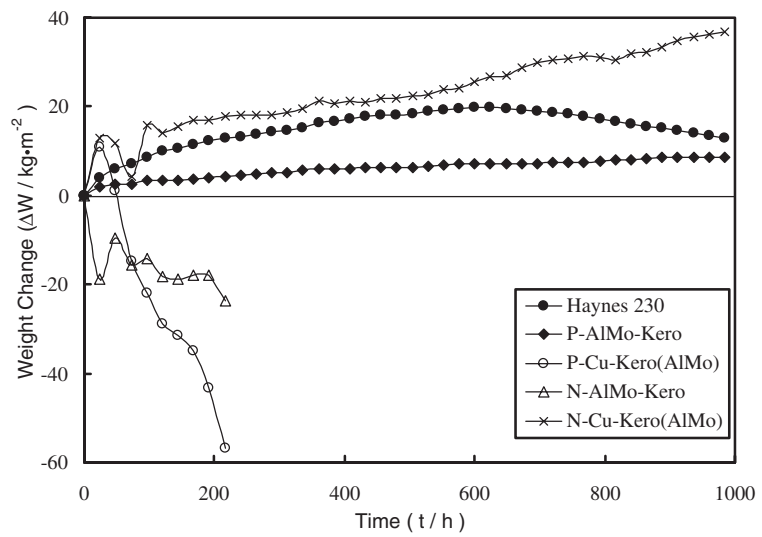

Fig. 10 The isothermal oxidation kinetics of unalloyed and various alloyed superalloy Haynes 230 specimens at $1000^{\circ} \mathrm{C}$ in static air. 
spallation. Additionally, the $\mathrm{N}-\mathrm{Cu}-\mathrm{Kero}(\mathrm{AlMo})$ exhibits uncertain weight-change data during the early stage of oxidation because the weight changes comprise a weight gain resulting from the formation of the metal oxides and a weight loss owing to the evaporation of carbon oxides such as $\mathrm{CO}$ and $\mathrm{CO}_{2}$. After 120 hours of exposure, the kinetic curve of this specimen shows a rapid and nearly linear weight gain due to numerous surface cracks and carbon oxide evaporation resulting in a porous alloyed layer.

\section{Conclusions}

(1) An alloyed layer with compositional gradient is successfully produced on the surface of the superalloy Haynes 230 during the EDA process by using Al-Mo composite electrode with positive polarity in pure kerosene dielectric. NiAl phase is the main constituent in the alloyed layer. Meanwhile, many discontinuous piled-layers with $\mathrm{Al}_{3} \mathrm{Mo}_{8}$ and $\mathrm{AlMo}_{3}$ phases form on the surface of the superalloy when negative electrode polarity is selected.

(2) The $\mathrm{Cr}_{23} \mathrm{C}_{6}, \mathrm{WC}_{1-x}$, and graphite phases exist in the alloyed layer of $\mathrm{N}-\mathrm{Cu}-\mathrm{Kero}(\mathrm{AlMo})$, while the $\mathrm{P}-\mathrm{Cu}-$ Kero(AlMo) specimen shows a solid solution phase as the raw superalloy by employing the EDA method of adding Al-Mo mixture powders in kerosene dielectric.

(3) The P-AlMo-Kero specimen shows the finest surface morphologies attributed to the fact that the alloying materials disintegrate from the Al-Mo composite electrode and mix with molten surface of the superalloy to smooth the surface and reduce crack formation.

(4) The P-AlMo-Kero has the highest surface hardness among the four EDA specimens, with maximum hardness of about $1100 \mathrm{HK}$. The increase in the surface hardness of P-AlMo-Kero results from the quenching effect and intermetallics formation in the alloyed layer.

(5) The ranking of high temperature oxidation resistance among all testing specimens, from best to worst, is as follows: P-AlMo-Kero, superalloy Haynes 230, N-CuKero(AlMo), P-Cu-Kero(AlMo), and N-AlMo-Kero.

(6) The P-AlMo-Kero specimen was produced under the optimum EDA conditions and displays the best surface alloying effect among the four EDA specimens, based on the composition and structure analyses, the hardness measurements, and the high temperature oxidation test.

\section{REFERENCES}

1) A. Gangadhar, M. S. Shunmugam and P. K. Philip: Wear 143 (1991) 45-55.

2) Y. Tsunekawa, M. Okumiya, N. Mohri and E. Kuribe: Mater. Trans., JIM 38 (1997) 630-635.

3) M. P. Samuel and P. K. Philip: International Journal of Machine Tools \& Manufacture 37 (1997) 1625-1633.

4) M. Okumiya, Y. Tsunekawa, K. Fukaya and N. Mohri: Mater. Trans. 42 (2001) 1717-1722.

5) Y. F. Tzeng and C. Y. Lee: International Journal of Advanced Manufacturing Technology 17 (2001) 586-592.

6) B. H. Yan, Y. C. Lin, F. Y. Huang and C. H. Wang: Mater. Trans. 42 (2001) 2597-2604

7) K. Furutani, A. Saneto, H. Takezawa, N. Mohri and H. Miyake: Precision Engineering 25 (2001) 138-144.

8) G. Boothroyd and A. K. Winston: Non-conventional machining processes in: Fundamentals of Machining and Machine Tools, (Marcel Dekker, Inc., New York, 1989) p. 491.

9) J. A. McGeough: Electrodischarge machining in: Advanced Methods of Machining, (Chapman \& Hall, London, 1988) p. 130.

10) Y. Tsunekawa, M. Okumiya, N. Mohri and I. Takahashi: Mater. Sci. Eng. A174 (1994) 193-198.

11) C. T. Sims and W. C. Hagel: The Superalloys, (John Wiley and Sons, Inc., New York, 1982).

12) S. Banerjee, U. D. Kulkarni and K. Urban: Acta Metall. 37 (1989) 3548.

13) U. D. Kulkarni, S. Muralidhar and S. Banerjee: Phys. Status Solidi (A) Applied Research 110 (1988) 331-345.

14) S. Naka, M. Thomas and T. Khan: Mater. Sci. Tech. 8 (1992) 291-298.

15) H. J. Grabke: Intermetallics 7 (1999) 1153-1158.

16) H. Habazaki, H. Mitsui, K. Ito, K. Asami, K. Hashimoto and S. Mrowec: Corros. Sci. 44 (2002) 285-301.

17) W. Kai and C. Y. Bai: J. Electrochem. Soc. 145 (1998) 2265-2275.

18) S. Mrowec: Oxi. Met. 44 (1995) 177.

19) JANAF Thermodynamical Tables, 3rd ed., American Chemical Society and American Institute of Physics for National Bureau of Standards, Washington, DC, 1986.

20) W. König, R. Wertheim and Y. Zvirin: Ann. CIRP 24 (1975) 95-100.

21) D. D. Dibitonto, P. T. Eubank, M. R. Patel and M. A. Barrufet: J. Appl. Phys. 66 (1989) 4095-4103.

22) M. R. Patel, M. A. Barrufet, P. T. Eubank and D. D. Dibitonto: J. Appl. Phys. 66 (1989) 4104-4111.

23) B. M. Schumacher: Ann. CIRP 39 (1990) 197-199.

24) H. M. Chow, B. H. Yan, F. Y. Huang and J. C. Hung: J. Mater. Proc. Technol. 101 (2000) 95-103.

25) B. H. Yan and C. C. Wang: J. of Mater. Proc. Technol. 95 (1999) 222231.

26) WebElements ${ }^{\mathrm{TM}}$, the periodic table on the WWW, URL: http://www.webelements.com/ Copyright 1993-2002 Mark Winter [The University of Sheffield and WebElements Ltd, UK].

27) M. K. Meyer and M. Akinc: J. Am. Ceram. Soc. 79 (1996) 938-944. 